\title{
Association between Asthma and Dental Caries amongst 12 - 15 Years Old Children: A School-Based Cross-Sectional Study in Karachi, Pakistan
}

\author{
Wajeeha Zahid ${ }^{*}$, Shafquat Rozi1 ${ }^{1}$, Farhan Raza Khan², Nida Zahid ${ }^{3}$, Masood Kadir ${ }^{1}$ \\ ${ }^{1}$ Department of Community Health Sciences, Aga Khan University, Karachi, Pakistan \\ ${ }^{2}$ Department of Surgery, Dentistry Section, Aga Khan University, Karachi, Pakistan \\ ${ }^{3}$ Department of Surgery, Aga Khan University, Karachi, Pakistan \\ Email: ^wajeeha.zahid@aku.edu, shafquat.rozi@aku.edu,farhan.raza@aku.edu,nida.zahid@aku.edu,masood.kadir@aku.edu
}

How to cite this paper: Zahid, W., Rozi, S., Khan, F.R., Zahid, N. and Kadir, M. (2019) Association between Asthma and Dental Caries amongst 12 - 15 Years Old Children: A School-Based Cross-Sectional Study in Karachi, Pakistan. Open Journal of Epidemiology, 9, 104-117.

https://doi.org/10.4236/ojepi.2019.91010

Received: January 18, 2019

Accepted: February 24, 2019

Published: February 27, 2019

Copyright $\odot 2019$ by author(s) and Scientific Research Publishing Inc. This work is licensed under the Creative Commons Attribution International License (CC BY 4.0).

http://creativecommons.org/licenses/by/4.0/

\begin{abstract}
Objective: The study aimed to determine an association between dental caries and asthma among 12 to 15 years old children. Methods: This is a school-based cross-sectional study conducted from January to February 2016. A random sample of 544 children aged 12 - 15 years were enrolled from five private schools of Karachi. Dental caries was assessed using DMFT Index (Decayed, Missing, Filled teeth). The main exposure variable was asthma and information on it was collected through the International Study of Asthma and Allergies in Childhood (ISAAC) questionnaire. Results: The data was analyzed using Cox Proportional Hazard algorithm. Crude and adjusted prevalence ratios with 95\% CI were reported. Total 554 children, 306 (56.3\%) boys and $43.7 \%$ girls participated in the study. Mean age of children was 13.2 \pm 0.05 years. Total number of children with DMFT $>0$ was $30.5 \%$. The decayed component contributed largely $(22.8 \%)$ to the DMFT score. Overall prevalence of asthma was $20 \%$. Prevalence of caries in asthmatic children was $28.4 \%$ as compared to $31 \%$ among non-asthmatic children. Adjusted prevalence ratio of dental caries in asthmatic children was 0.8 (95\% CI $0.6-1.3$ ) after adjusting for carious food intake, age, oral hygiene index and dentist visit; the association between asthma and dental caries turned out to be in-significant. There was significant interaction between maternal education and consumption of cariogenic food and also between child's age and oral hygiene ( $\mathrm{p}$-value $<0.1$ ). Conclusions: There was no association observed between asthma and dental caries among the children examined in this study.
\end{abstract}

\section{Keywords}

Dental Caries, Asthma, Children 


\section{Introduction}

Asthma is a common respiratory disease of childhood [1]. Approximately 300 million individuals globally suffer from asthma [2]. International Study of Asthma and Allergies in Children (ISAAC) surveyed 1.2 million children from 98 countries and reported that prevalence of asthma is $14.1 \%$ among $13-14$ years old children [3]. The overall prevalence of asthma in Pakistan among 3 17 years old is around $10.2 \%$ [4]. According to a Pakistani study, the prevalence of physician diagnosed asthma in school-going children aged 3 to 16 years is $15 \%$ [5]. Among pre-pubertal males, asthma is twice as common compared to females but later during adolescence, it affects both genders almost equally [6].

Dental caries is one of the most prevalent chronic diseases among children. It affects children both physically and psychologically. It influences the child's dietary intake impairing the growth and development [7]. Moreover, it also affects the self-esteem and quality of life of children [8] [9]. Caries ranks as the fourth most expensive disease to treat in some developing countries. The treatment cost of caries alone is higher than the total health budget of these countries [8].

Findings from the earlier studies on the association of dental caries with asthma are inconsistent; few have found positive association [10] [11] whilst others have not [12] [13] [14]. It has been suggested that asthmatics are susceptible to developing dental caries because the anti-asthmatic medications, the drug chemistry, its low $\mathrm{pH}$ [15], sugar content [16] and its effect on the salivary flow [17] may increase the vulnerability of caries among asthmatics. Moreover, asthmatics may consume more erosive drinks [18] or their practice of mouth breathing may be the reason for higher caries experience [19]. The possible reasons for conflicting results might be varying clinical presentations, diagnostic challenges and complex etiologies of the two chronic conditions. Alternatively, the lack of association in different studies could be attributed to insufficient sample size, inconsistent age groups, differences in the severity of asthma, use of other medications and participants belonging to different ethnicities.

Hence, it's important to identify association between the two diseases so that prophylactic strategies can be formulated to advocate for adherence to precautionary measures by asthmatics to avert undesirable effects on oral tissues. Therefore, the aim of this study was to determine an association between dental caries and asthma among 12 to 15 years old children.

\section{Material and Methods}

Across-sectional study was conducted from January to May 2016, among children aged 12 to 15 years from five private schools of high socio-economic areas in Karachi, Pakistan.

\section{Inclusion and Exclusion Criteria of the participants}

Only those students were included who gave assent and their parents provided written consent. We excluded children who were suffering from respiratory diseases other than asthma or any other serious medical illness (e.g. epilepsy) that 
require medications that have anti-sialagogue effect, as it would cloud the study results. Children with history dento-facial or skeletal deformities such as cleft lip/palate or any congenital dysplasia were also excluded as they exhibit abnormal morphology of tooth and unusual eruption patterns and their defective tooth structure makes them more prone to caries [20].

\section{Sample size and sampling strategy}

Students of grade VI to XI were selected through simple random sampling from five schools. A minimum sample size of 513 was required to achieve $80 \%$ power, $5 \%$ level of significance, considering an anticipated prevalence of asthma in Pakistan as 14\% among children aged 12 - 15 years [4] and expected prevalence ratio of 2.5 adding non response of $10 \%$. The sample size was inflated to compensate for refusals. The final sample size was 544 children.

\section{Main exposure variable (Definition of asthmatics)}

Asthma is a chronic condition due to inflammation of the air passages in the lungs. In an attack, the lining of the passages swell causing the airways to narrow, reducing the airflow in the lungs [21].

\section{Definition of Outcome variable}

Dental caries is localized destruction of susceptible dental hard tissues by acidic by-products from bacterial fermentation of dietary carbohydrates" [22] defined as the sum of all decayed, missing and filled teeth in the oral cavity assessed by clinical dental examination.

We categorized DMFT Index as a binary outcome (DMFT $<1=$ Caries Absent and DMFT $\geq 1=$ Caries Present) [23].

\section{Data Collection procedure/tool}

A pretested self-administered questionnaire was used to collect the information on the potential risk factors of caries. Data regarding asthma (main exposure variable) was collected through the International Study of Asthma and Allergies in Childhood (ISAAC) questionnaire [24]. It comprised of eight items and each item is assigned a score from 0 to 2 and an overall score from 6 to 14 classifies the child as an asthmatic. The ISAAC questionnaire assesses the history of wheeze ever, asthma and dry cough, the frequency of wheeze attacks in the past 12 months, disturbance of speech or sleep related to wheeze and wheezing followed by exercise [24]. Participants oral examination was conducted to assess dental caries (the study outcome) by the qualified dentists. It was done using disposable dental kits which included mouth mirror, probe, tweezers and cotton swabs along with rechargeable flashlights. The decayed, missing and filled teeth (DMFT Index) was recorded. According to World Health Organization (WHO) the aggregate of decayed, missing and filled teeth (DMFT) till date remains one of the main index for assessing oral health [25]. Plaque and calculus were also recorded to measure dental hygiene status of school children. Later Simplified Oral Hygiene Index (OHI-S) (sum of Debris and Calculus Index and divided by 6) was calculated to determine oral hygine status (Good: 0 to 1.2; Fair: 1.3 to 3; and Poor: 3 to 6$)$. 
Anthropometric measurements such as Height (in feet) measured with an angled scale and weight (in kilogram) was measured using a bathroom scale to calculate BMI.

\section{Questionnaire}

The questionnaire addressed child's gender, age, parents education, physician diagnoses of asthma, duration of asthma, type of medication administered and its frequency, family history of asthma and allergies, dietary habits (amount and frequency of intake of each carious food item using Food Frequency Questionnaire (FFQ) and oral hygiene behavior (assessed by tooth brushing frequency, dental visits and the reason for last visit). Additionally the mother of the children were interviewed via telephone regarding physician diagnoses of asthma, duration of asthma, past and current medication and its frequency, family history of asthma and mouth-breathing. Comprehensibility and clarity of questions were assessed through pre-testing.

\section{Ethical Consideration}

The study was approved by the Ethical Review Committee of the Aga Khan University Hospital. Children who were identified as asthmatics using ISAAC questionnaire were later contacted at home to inform their parents so that they could seek advice from a pulmonologist.

\section{Data editing and entry}

The filled questionnaires were edited by principal investigator and the data collectors both in field and office and any missing data were clarified immediately. Data was double entered by two data entry operators in Epi Info V.6.04. [26].

\section{Statistical analysis}

STATA version 11.0 was used for data analysis. For categorical variables, frequencies and percentages were reported whereas for quantitative variables means and standard deviations were computed.

Factor analysis was used to analyze FFQ. The food score was divided into 4 categories depending on the consumption of junk food, sugary items and milk related products. Those children who consumed highest amount of cariogenic food belonged to food score category 4 .

Prevalence Ratio (PRs) and their 95\% confidence intervals (CIs) was calculated using Cox Proportional hazard algorithm. We used Cox proportional hazard algorithm and reported Prevalence ratio instead of Odds ratio as it is overestimated in cross-sectional studies when the outcome is frequent as in our case the prevalence of caries is 55\% [27]. When every participant is assigned a constant risk period in Cox algorithm, the hazard rate ratio is equivalent to prevalence ratio in cross-sectional studies.

All variables having p-value less than 0.25 were included in the model. All biological plausible interactions were checked at 0.05 level of significance. Significant interaction was found between age \& oral hygiene and mothers education \& carious food consumption and kept in the model. 


\section{Results}

There were 544 children, 306 (56.25\%) boys and 238 (43.75\%) girls. The mean age of children was $13.2 \pm 0.05$ years. The prevalence of overweight and obese children was $18.6 \%$ and $11.9 \%$ respectively. Nearly $51 \%$ mothers were university graduates (Table 1).

The prevalence of physician's diagnosed asthma was $11.9 \%$. Approximately $6.6 \%$ children were identified as asthmatics on ISAAC tool and $1.5 \%$ children were revealed as asthmatics at interview with the parents. Thus, the overall prevalence of asthma was $20 \%$. Wheeze during or after exercise was the most commonly reported symptom. Approximately $38 \%$ children had family history of asthma. One fourth of the children were allergic. About $58 \%$ children reported dust allergy (followed by 16\% food allergy and 7\% fur allergy).

For oral hygiene practices, $68.3 \%$ children reported brushing their teeth at least twice a day. Nearly $61 \%$ children had good oral hygiene, $37 \%$ fair oral hygiene and only $2 \%$ had poor oral hygiene (according to Simplified Oral Hygiene Index). The prevalence of caries was $30.51 \%$.

The mean duration of medication use was 5.3 years. Only 26/109 (4.78\%) asthmatics children had long term ( $>5$ years) asthma (Table 2$)$. The most common form of medication used among asthmatic children was inhaler.

The prevalence of caries was 1.39 times higher among children with acceptable oral hygiene compared to those with good oral hygiene ( $\mathrm{PR}=1.39 ; \mathrm{CI}=1.02$ - 1.90) as shown in Table 3. Children who consumed high amount of cariogenic food were $71 \%$ more likely to have caries compared to those who consumed less amount of junk food and sugary items $(P R=1.71 ; C I=1.10-2.66)$. Main exposure variable (asthma) turned out to be insignificant at bivariate level ( $\mathrm{p}$-value $>$ 0.25).

The final Cox proportional hazard algorithm model shows that the adjusted prevalence ratio of dental caries among asthmatic children compared to non-asthmatic children was 0.86 (95\% CI: 0.6 - 1.3). After adjusting for age, prior visit to the dentist, oral hygiene and cariogenic food consumption, the prevalence of caries was 1.51 times higher among children who regularly visit the dentist compared to those who don't (adjusted PR $=1.51 ; 95 \% \mathrm{CI}=1.05$ 2.17). Among children whose mothers education was at least high school and the cariogenic food consumption was high, the prevalence of caries was 6.8 times greater than children whose mothers education was similar but cariogenic food consumption was low (adjusted PR $=6.8 ; 95 \% \mathrm{CI}=1.64$ - 29.67). Among children aged 12 to 13 years old and fair oral hygiene the prevalence of caries was 2.7 times greater than children aged 15 years and fair oral hygiene (adjusted PR = $1.395 \% \mathrm{CI}=0.7-2.6)($ Table 4$)$.

\section{Discussion}

This study was aimed to evaluate an association between asthma and dental caries among school children aged 12 to 15 years studying at five private schools in 
Table 1. Descriptive analysis of participant's characteristics, socio-demographic status, asthma and other variables, oral hygiene practices and oral health status in Karachi, Pakistan $(\mathrm{n}=544)$.

\begin{tabular}{|c|c|c|}
\hline Participant's characteristics & Frequency & (\%) \\
\hline \multicolumn{3}{|l|}{ Age } \\
\hline 12 years & 191 & 35.11 \\
\hline 13 years & 150 & 27.57 \\
\hline 14 years & 102 & 18.75 \\
\hline 15 years & 101 & 18.57 \\
\hline Age in years $($ Mean $\pm S D)$ & $13.2 \pm 0.04$ & \\
\hline \multicolumn{3}{|l|}{ Gender } \\
\hline Male & 306 & 56.25 \\
\hline Female & 238 & 43.75 \\
\hline \multicolumn{3}{|l|}{ Education of Mother } \\
\hline High school and below & 265 & 48.71 \\
\hline Graduation and above & 279 & 51.29 \\
\hline \multicolumn{3}{|l|}{ Education of Father } \\
\hline High school and below & 55 & 10.11 \\
\hline Graduation and above & 489 & 89.89 \\
\hline \multicolumn{3}{|l|}{ BMI } \\
\hline Underweight & 56 & 10.29 \\
\hline Normal weight & 322 & 59.19 \\
\hline Overweight \& obese & 166 & 30.52 \\
\hline BMI $($ Mean \pm SD $)$ & $20.44 \pm 0.19$ & \\
\hline Physician diagnosed Asthma & 65 & 11.9 \\
\hline ISAAC questionnaire & 36 & 6.6 \\
\hline Parent interviews (childhood asthma) & 8 & 1.5 \\
\hline Asthma $^{*}$ & 109 & 20 (95\% CI: $17 \%-23 \%)$ \\
\hline Family history of asthma & 206 & 37.9 \\
\hline Allergy status of child & 136 & 25 \\
\hline \multicolumn{3}{|l|}{ Brushing frequency/day } \\
\hline$>1$ time & 372 & 68.3 \\
\hline 1 time & 172 & 31.6 \\
\hline Had dental visit & 370 & 68.0 \\
\hline \multicolumn{3}{|l|}{ Oral Hygiene Index } \\
\hline Good $(0$ to $<1.2)$ & 330 & 60.6 \\
\hline Fair $(>1.2$ to $<3)$ & 201 & 36.9 \\
\hline Poor $(>3)$ & 13 & 2.4 \\
\hline Caries & 166 & 30.51 \\
\hline
\end{tabular}

*Asthma includes physician diagnosed + wheeze in 12 months (ISAAC) + childhood asthma (parent interviews). 
Table 2. Descriptive Analysis of medication among 12 - 15 years old asthmatic children in Karachi, Pakistan $(\mathrm{n}=544)$.

\begin{tabular}{|c|c|c|}
\hline Variable & Frequency & $\%$ \\
\hline \multicolumn{3}{|l|}{ Asthma status } \\
\hline Non-asthmatics & 435 & 79.9 \\
\hline Asthmatics & 109 & 20.1 \\
\hline \multicolumn{3}{|l|}{ Medications among asthmatics } \\
\hline No & 37 & 6.80 \\
\hline Yes & 72 & 13.24 \\
\hline \multicolumn{3}{|l|}{ Duration of medication (years) } \\
\hline Non-asthmatics & 435 & 79.96 \\
\hline Asthmatics (newly identified) & 36 & 6.62 \\
\hline \multicolumn{3}{|l|}{ Asthmatics } \\
\hline$<1$ year & 12 & 2.21 \\
\hline $2-5$ years & 35 & 6.43 \\
\hline$>5$ years & 26 & 4.78 \\
\hline$($ Mean $\pm S D)$ & $5.31 \pm 0.50$ & \\
\hline \multicolumn{3}{|l|}{ Type of medication ${ }^{*}$} \\
\hline \multicolumn{3}{|l|}{ Inhaler } \\
\hline Non-asthmatic & 435 & 79.96 \\
\hline Never User & 49 & 9.01 \\
\hline Regular User ${ }^{* *}$ & 13 & 2.39 \\
\hline Occasional User*** & 47 & 8.64 \\
\hline \multicolumn{3}{|l|}{ Syrup } \\
\hline Non-asthmatic & 435 & 79.96 \\
\hline Never User & 97 & 17.83 \\
\hline Regular User ${ }^{* *}$ & 3 & 0.55 \\
\hline Occasional User ${ }^{* * *}$ & 9 & 1.65 \\
\hline
\end{tabular}

${ }^{\star}$ Multiple responses; ${ }^{* *}$ Regular User-Twice/Once; ${ }^{* * *}$ Occasional User-only during attack.

Table 3. Bivariate analysis for factors associated with dental caries using Cox Proportional Hazard Algorithm $(\mathrm{n}=544)$.

\begin{tabular}{ccc}
\hline Variables & Prevalence of Caries n (\%) & Crude Prevalence Ratio (95\% CI) \\
\hline Age & & 1 \\
12 years (ref) & $44(23.04)$ & $1.51(1.01-2.25)$ \\
13 years & $52(34.67)$ & $1.45(0.93-2.26)$ \\
14 years & $34(33.33)$ & $1.55(0.99-2.40)$ \\
15 years & $36(35.64)$ & 1 \\
Dental visit & & $1.48(1.037-2.11)$ \\
No (ref) & $40(22.99)$ & 1 \\
Yes & $126(34.05)$ & $1.39(1.02-1.90)$ \\
Oral Hygiene Index & & $1.46(0.59-3.59)$ \\
Good $(0$ to $\leq 1.2)($ ref $)$ & $87(26.36)$ & \\
Fair $(>1.2$ to $\leq 3)$ & $74(36.82)$ & \\
Poor $(>3)$ & $5(38.46)$ & \\
\hline
\end{tabular}




\section{Continued}

\begin{tabular}{ccc}
\hline Cariogenic Food & & \\
Low Consumption & $31(22.79)$ & 1 \\
Medium Consumption & $41(30.15)$ & $1.32(0.83-2.11)$ \\
High Consumption & $53(38.97)$ & $1.71(1.10-2.66)$ \\
Highest Consumption & $41(30.15)$ & $1.32(0.83-2.11)$ \\
\hline
\end{tabular}

Table 4. Multivariate analysis for predictor variables associated with dental caries using Cox Proportional Hazard Algorithm $(\mathrm{n}=544)$.

\begin{tabular}{|c|c|c|}
\hline \multicolumn{2}{|c|}{ Variables } & $\begin{array}{l}\text { Adjusted Prevalence } \\
\text { Ratio }(95 \% \mathrm{CI})\end{array}$ \\
\hline \multicolumn{3}{|c|}{ Asthma } \\
\hline \multicolumn{2}{|c|}{ No } & 1 \\
\hline \multicolumn{2}{|c|}{ Yes } & $0.86(0.6-1.3)$ \\
\hline \multicolumn{3}{|c|}{ Dental visit } \\
\hline \multicolumn{2}{|c|}{ No } & 1 \\
\hline \multicolumn{2}{|c|}{ Yes } & $1.51(1.05-2.17)$ \\
\hline \multicolumn{3}{|c|}{ Maternal Education and Cariogenic Food Consumption } \\
\hline \multirow[t]{4}{*}{ Graduate and } & Lowest Consumption & 1 \\
\hline & Medium Consumption & $1.2(0.6-2.3)$ \\
\hline & High Consumption & $1.4(0.7-2.6)$ \\
\hline & Highest Consumption & $1.6(0.9-2.9)$ \\
\hline \multirow[t]{4}{*}{ Intermediate and } & Lowest Consumption & $0.3(0.1-1.5)$ \\
\hline & Medium Consumption & $5.3(1.6-17.3)$ \\
\hline & High Consumption & $6.8(1.6-29.7)$ \\
\hline & Highest Consumption & $2.1(0.4-10.1)$ \\
\hline \multirow[t]{4}{*}{ Matric/O-levels and } & Lowest Consumption & $1.3(0.6-2.8)$ \\
\hline & Medium Consumption & $0.9(0.4-2.1)$ \\
\hline & High Consumption & $1.6(0.7-3.5)$ \\
\hline & Highest Consumption & $1.0(0.4-2.4)$ \\
\hline \multicolumn{3}{|c|}{ Oral Hygiene Index and Age } \\
\hline \multirow[t]{4}{*}{ Good hygiene and } & 12 years & 1 \\
\hline & 13 years & $0.9(0.5-1.6)$ \\
\hline & 14 years & $1.5(0.8-2.6)$ \\
\hline & 15 years & $1.3(0.7-2.4)$ \\
\hline \multirow[t]{4}{*}{ Fair hygiene and } & 12 years & $1.0(0.6-1.9)$ \\
\hline & 13 years & $2.7(1.4-4.4)$ \\
\hline & 14 years & $0.9(0.4-1.8)$ \\
\hline & 15 years & $1.3(0.7-2.6)$ \\
\hline \multirow[t]{4}{*}{ Poor hygiene and } & 12 years & $1.4(0.3-6.1)$ \\
\hline & 13 years & $4.7(0.6-37.5)$ \\
\hline & 14 years & $6.9 \mathrm{e}-14(-32.14-28.45)$ \\
\hline & 15 years & $1.4(0.3-6.3)$ \\
\hline
\end{tabular}


Karachi, Pakistan. We did not find any association between asthma and caries. Our findings are comparable with the studies conducted by Eloot et al. [28], Meldrum et al. [13] Shulman et al. [29] and Bjerkeborn et al. [30] who also failed to detect any significant dissimilarity in caries experience between asthmatic and non-asthmatic children. On the contrary, findings from other studies suggest a relationship between asthma and caries [31].

The probable reason for inconsistent results regarding the association might be that asthma is seasonal in nature and it's difficult to examine any relationship of asthma with other diseases. The disease itself, its severity and medications fluctuate over time. In addition, it's difficult to assess the initiation of the disease. Moreover, a universally accepted definition of asthma does not exist. Estimation through symptoms is what surveys of asthma rely on. In our study too, we relied upon the information given by the students and their parents regarding the asthma status.

Caries prevalence in the present study was $30.5 \%$. This is comparable to the study by Charani et al. [32] who reported a prevalence of $29 \%$ among children enrolled in schools located in similar affluent settings. Naidu et al. [33] reported e prevalence of $29.1 \%$ among 3 - 5 years old Indians residing in Caribbean area. Kutesa et al. [34] reported caries prevalence of 32.5\% among 11 to 13 years old school children. Our estimates are lower than Mohiuddin et al. [35] who reported an overall prevalence of $69.6 \%$ among 6 to 12 year-old. Similarly, Abbas et al. [36] who reported 64.6\% prevalence of caries among 11 to 16 year old children of Karachi. A possible explanation for such low prevalence of caries among our study participants could be due to better awareness regarding oral hygienepractices and access to dental care as majority of our study participants belonged to high socio-economic status. They reported to have increased frequency of tooth brushing, availability of fluoridated toothpastes and above all educated parents, all of which add to the protection against dental caries [37].

In our study child's age, previous dental visits, oral hygiene index and cariogenic food consumption were significantly associated with the dental caries. Caries prevalence was higher in children who had visited a dentist than those who had not. This was due to the fact that children with carious teeth visited the dentist more often to get the required treatment [38].

Furthermore, variables such as oral hygiene, child's age, maternal education and cariogenic food consumption were effect modifiers in our study. The association of cariogenic food consumption and caries varies by the level of maternal education. The lower the educational status of the mother, the higher was the child's consumption of unhealthy cariogenic food. The mother's years of education had a direct relationship with the selection of healthy fruits and vegetables consumption among children [39].

Children aged 12 to 13 years old had very high debris scores in the oral cavity as compared to those aged 15 years. A probable reason for this improvement in oral cleanliness maybe due to the fact that young adults become more conscious about their appearance as they desired to be socially accepted. 
The duration of asthmatic medications had no effect on the caries experience. These results were similar to the finding from Eloot et al. [28] who reported that length of the disease or medication of asthma has no significant effect on the caries development. Ersin et al. [17] demonstrated a positive correlation between duration of asthma and S. mutans count in saliva and a negative relationship between duration of medication and $\mathrm{pH}$ of saliva among individuals having caries.

Another finding of the present study is that the type of medication used (inhaler or syrup) or its dosage has no effect on dental caries. This finding is in agreement to Eloot et al. [28]. However, on the contrary, Reddy et al. [40] reported that caries prevalence was the highest among children taking medication in the form of syrup. Moreover, Tootla et al. [41] found that only lactose based dry powder inhalers lower the $\mathrm{pH}$ of saliva below 5.5, resulting in demineralization of enamel. Ryberg et al. [42] reported impaired salivary secretion in asthmatics up to $20 \%$ decrease in secretory rates of stimulated whole saliva. However, the results of these studies are not comparable to the present study as the children in our study were using oral anti asthmatic medications intermittently, most of them were on combination therapy and there were frequent alterations in the form and dosage of medication, so individual effect of drug could not be evaluated. In addition the most common form of medication was inhaler and very low proportion of children in our study were using syrups (only 3 regular users and 9 occasional users). In the present study, we did not find any association between caries prevalence and the severity of asthma.

The strengths of our study included data collectors who were blinded regarding the exposure status (asthma) of children at the time of caries examination. This prevented differential misclassification (information bias) on the exposure status. Moreover, we reported prevalence ratios (PR) along with 95\% CI. Methodologically, in a cross sectional study, $\mathrm{PR}$ is the recommended alternative to Odds Ratio, provided the outcome of interest is frequent [27].

There were some limitations too in the present study. Firstly, asthma was assessed via questionnaire rather than an objective measure like Spirometer. Since, asthma information was collected via questionnaire, thus it was mainly dependent on the parent or child ability to recall, and this could have led to s recall bias resulting in under or over reporting. To overcome this, we assessed asthma via ISAAC, physician diagnosis and parent interviews. Secondly, assessment of dental caries was done using DMFT index. No dental radiographs were employed for the logistic reasons. Thus, we might have under-estimated the actual magnitude of dental caries. However, reported sensitivity and specificity of DMFT Index is 1.0 and 0.65 to 0.80 , respectively [43]. Moreover, this study was conducted in schools located in the most affluent areas of Karachi due to law and order situation of the country public schools were reluctant to grant permission for data collection. Socioeconomic status (SES) disproportionately affects dental caries so by taking a homogenous population in terms of SES, aided in controlling for the confounding at the design stage. 


\section{Conclusion}

No statistically significant association could be found between asthma and dental caries. Longitudinal studies are needed to explore the role of asthma in dental caries.

\section{Acknowledgements}

We acknowledge all selected schools, students and parents for their participation and are indebted to the dentists of JSMU and our data collection team for their contribution. Sincere gratitude to Mr Iqbal Azam, Dr Nida Zahid, Dr Ana Nayani, Dr Faraz Siddiqui and Dr Tahir Yousufzai for their support and guidance.

\section{Author's Note}

$\mathrm{WZ}$ was the principal investigator of the study and conducted this study as part of her MSc Epidemiology \& Biostatistics thesis project. She carried out the study conception, design, data analysis, interpretation of data and drafted the manuscript. MMK, has contributed in conception and design, and reviewing manuscript critically. SR was responsible for design, sample size estimation, data analysis, interpretation of data and reviewing the manuscript. FRK contributed in the design of the study and manuscript review. NZ read and approved the final manuscript.

\section{Conflicts of Interest}

None declared.

\section{Data Sharing Statement}

No additional unpublished data is available from the study. The data of this study is with the first author of the manuscript.

\section{Funding}

Department of Community Health Sciences, Aga Khan University provided the funding for the study.

\section{References}

[1] Haugejorden, O. and Magne Birkeland, J. (2006) Ecological Time-Trend Analysis of Caries Experience at 12 Years of Age and Caries Incidence from Age 12 to 18 Years: Norway 1985-2004. Acta Odontologica, 64, 368-375. https://doi.org/10.1080/00016350600856083

[2] Masoli, M., Fabian, D., Holt, S. and Beasley, R. (2004) Global Initiative for Asthma P. The Global Burden of Asthma: Executive Summary of the GINA Dissemination Committee Report. Allergy, 59, 469-478. https://doi.org/10.1111/j.1398-9995.2004.00526.x

[3] Mallol, J., Crane, J., von Mutius, E., et al. (2013) The International Study of Asthma and Allergies in Childhood (ISAAC) Phase Three: A Global Synthesis. Allergologia 
et Immunopathologia, 41, 73-85. https://doi.org/10.1016/j.aller.2012.03.001

[4] Khan, A.A., Tanzil, S., Jamali, T., et al. (2014) Burden of Asthma among Children in a Developing Megacity: Childhood Asthma Study. Pakistan Journal of Asthma, 51, 891-899. https://doi.org/10.3109/02770903.2014.930882

[5] Hasnain, S.M., Khan, M., Saleem, A., et al. (2009) Prevalence of Asthma and Allergic Rhinitis among School Children of Karachi, Pakistan, 2007. Journal of Asthma, 46, 86-90. https://doi.org/10.1080/02770900802513023

[6] Subbarao, P., Mandhane, P.J. and Sears, M.R. (2009) Asthma: Epidemiology, Etiology and Risk Factors. Canadian Medical Association Journal, 181, E181-E90. https://doi.org/10.1503/cmaj.080612

[7] Bagramian, R.A., Garcia-Godoy, F. and Volpe, A.R. (2009) The Global Increase in Dental Caries. A Pending Public Health Crisis. American Journal of Dentistry, 22, 3-8.

[8] Kathmandu, R.Y. (2002) The Burden of Restorative Dental Treatment for Children in Third World Countries. International Dental Journal, 52, 1-9. https://doi.org/10.1111/j.1875-595X.2002.tb00589.x

[9] Cunnion, D.T., Spiro, A., Jones, J.A., et al. (2010) Pediatric Oral Health-Related Quality of Life Improvement after Treatment of Early Childhood Caries: A Prospective Multisite Study. Journal of dentistry for Children, 77, 4-11.

[10] Hamid, S.M., Elhassan, F.E. and Hassan, A. (2015) Dental Caries in 3-12-Year-Old Sudanese Children with Bronchial Asthma. Journal of Dental Research and Review, 2, 167. https://doi.org/10.4103/2348-2915.176681

[11] Shashikiran, N.D., Reddy, V. and Raju, P.K. (2007) Effect of Antiasthmatic Medication on Dental Disease: Dental Caries and Periodontal Disease. Journal of Indian Society of Pedodontics and Preventive Dentistry, 25, 65. https://doi.org/10.4103/0970-4388.33450

[12] Tanaka, K., Miyake, Y., Arakawa, M., et al. (2008) Dental Caries and Allergic Disorders in Japanese Children: The Ryukyus Child Health Study. Journal of Asthma, 45, 795-799. https://doi.org/10.1080/02770900802252119

[13] Meldrum, A.M., Thomson, W.M., Drummond, B.K., et al. (2001) Is Asthma a Risk Factor for Dental Caries? Findings from a Cohort Study. Caries Research, 35, 235-239. https://doi.org/10.1159/000047463

[14] Shulman, J.D., Taylor, S.E. and Nunn, M.E. (2001) The Association between Asthma and Dental Caries in Children and Adolescents: A Population-Based Control Study. Caries Research, 35, 240-246. https://doi.org/10.1159/000047464

[15] O’sullivan, E.A. (1998) Curzon ME. Drug Treatments for Asthma May Cause Erosive Tooth Damage. BMJ, 317, 820. https://doi.org/10.1136/bmj.317.7161.820

[16] Storhaug, K. (1985) Caries Experience in Disabled Pre-School Children. Acta Odontologica Scandinavica, 43, 241-248. https://doi.org/10.3109/00016358509046504

[17] Ersin, N.K., Guelen, F., Eronat, N., et al. (2006) Oral and Dental Manifestations of Young Asthmatics Related to Medication, Severity and Duration of Condition. $\mathrm{Pe}$ diatrics International, 48, 549-554. https://doi.org/10.1111/j.1442-200X.2006.02281.x

[18] McDerra, E., Pollard, M. and Curzon, M. (1998) The Dental Status of Asthmatic British School Children. Pediatric Dentistry, 20, 281-287.

[19] Emslie, R.D., Massler, M. and Zwemer, J.D. (1952) Mouth Breathing: I. Etiology and Effects (A Review). The Journal of the American Dental Association, 44, 506-521. 
https://doi.org/10.1111/j.1398-9995.2004.00526.x

[20] Mazzoleni, S., Stellini, E., Cavaleri, E., et al. (2008) Dental Caries in Children with Asthma Undergoing Treatment with Short-Acting ÃŸ2-Agonists. European Journal of Paediatric Dentistry, 9, 132-138.

[21] Bush, A. and Zar, H.J. (2011) WHO Universal Definition of Severe Asthma. Current Opinion in Allergy and Clinical Immunology, 11, 115-121. https://doi.org/10.1097/ACI.0b013e32834487ae

[22] Fejerskov, O. (1997) Concepts of Dental Caries and Their Consequences for Understanding the Disease. Community Dentistry and Oral Epidemiology, 25, 5-12. https://doi.org/10.1111/j.1600-0528.1997.tb00894.x

[23] Pandit, P. and Javali, S.B. (2012) Multiple Logistic Regression Model to Predict Risk Factors of Oral Health Diseases. Romanian Statistical Review, 5, 1-14.

[24] Solé, D., Vanna, A., Yamada, E., et al. (1998) International Study of Asthma and Allergies in Childhood (ISAAC) Written Questionnaire: Validation of the Asthma Component among Brazilian Children. Journal of Investigational Allergology \& Clinical Immunology, 8, 376-382.

[25] Klein, H. and Palmer, C.E. (1940) Studies on Dental Caries: X. A Procedure for the Recording and Statistical Processing of Dental Examination Findings. Journal of Dental Research, 19, 243-256. https://doi.org/10.1177/00220345400190030401

[26] Dean, A.G. (1996) Epi Info, Version 6: A Word-Processing, Database, and Statistics Program for Public Health on IBM-Compatible Microcomputers.

[27] Barros, A.J. and Hirakata, V.N. (2003) Alternatives for Logistic Regression in Cross-Sectional Studies: An Empirical Comparison of Models That Directly Estimate the Prevalence Ratio. BMC Medical Research Methodology, 3, 21. https://doi.org/10.1186/1471-2288-3-21

[28] Eloot, A., Vanobbergen, J., De Baets, F., et al. (2004) Oral Health and Habits in Children with Asthma Related to Severity and Duration of Condition. European Journal of Paediatric Dentistry, 5, 210-215.

[29] Shulman, J.D., Taylor, S. and Nunn, M. (2001) The Association between Asthma and Dental Caries in Children and Adolescents: A Population-Based Case-Control Study. Caries Research, 35, 240-246. https://doi.org/10.1159/000047464

[30] Bjerkeborn, K., Dahllof, G., Hedlin, G., et al. (1987) Effect of Disease Severity and Pharmacotherapy of Asthma on Oral Health in Asthmatic Children. European Journal of Oral Sciences, 95, 159-164. https://doi.org/10.1111/j.1600-0722.1987.tb01824.x

[31] Ryberg, M., MÃller, C. and Ericson, T. (1987) Effect of $\hat{I}^{2} 2$-Adrenoceptor Agonists on Saliva Proteins and Dental Caries in Asthmatic Children. Journal of Dental Research, 66, 1404-1406. https://doi.org/10.1177/00220345870660082401

[32] Charani, A., Mohsin, S., Sufia, S., et al. (2011) Prevalence of Early Childhood Caries among 3-5-Year Old Children of Clifton, Karachi. Journal of the Pakistan Dental Association, 20, 89-92.

[33] Naidu, R., Nunn, J. and Kelly, A. (2013) Socio-Behavioural Factors and Early Childhood Caries: A Cross-Sectional Study of Preschool Children in Central Trinidad. BMC Oral Health, 13, 30. https://doi.org/10.1186/1472-6831-13-30

[34] Kutesa, A., Kasangaki, A., Nkamba, M., et al. (2015) Prevalence and Factors Associated with Dental Caries among Children and Adults in Selected Districts in Uganda. African Health Sciences, 15, 1302-1307.

https://doi.org/10.4314/ahs.v15i4.33 
[35] Mohiuddin, S., Nisar, N. and Dawani, N. (2015) Dental Caries Status among 6 and 12 Years Old School Children of Karachi City. Journal of the Pakistan Dental Association, 24, 39-45.

[36] Abbas, A., Syed, I.B., Abbas, H., et al. (2015) Malocclusion and Its Relationship with Dental Caries in a Sample of Pakistani School Children. Pakistan Oral \& Dental Journal, 35, 216-219.

[37] Edelstein, B.L. (2006) The Dental Caries Pandemic and Disparities Problem. BMC Oral Health, 6, S2. https://doi.org/10.1186/1472-6831-6-S1-S2

[38] Meera, R., Muthu, M.S., Phanibabu, M., et al. (2008) First Dental Visit of a Child. Journal of Indian Society of Pedodontics and Preventive Dentistry, 26, 68.

[39] Cribb, V.L., Jones, L.R., Rogers, I.S., et al. (2011) Is Maternal Education Level Associated with Diet in 10-Year-Old Children? Public Health Nutrition, 14, 2037-2048. https://doi.org/10.1017/S136898001100036X

[40] Reddy, D.K., Hegde, A.M. and Munshi, A. (2003) Dental Caries Status of Children with Bronchial Asthma. The Journal of Clinical Pediatric Dentistry, 27, 293-295.

[41] Tootla, R., Toumba, K.J. and Duggal, M.S. (2004) An Evaluation of the Acidogenic Potential of Asthma Inhalers. Archives of Oral Biology, 49, 275-283. https://doi.org/10.1016/j.archoralbio.2003.11.006

[42] Ryberg, M., MÃ-Ller, G. and Erigson, T. (1991) Saliva Composition and Caries Development in Asthmatic Patients Treated with $\hat{\mathrm{I}}^{2} 2 \hat{a}-$ Adrenoceptor Agonists: A 4â-Year Followâ up Study. European Journal of Oral Sciences, 99, 212-218. https://doi.org/10.1111/j.1600-0722.1991.tb01887.x

[43] Cypriano, S., Sousa, Md.L.Rd. and Wada, R.S. (2005) Evaluation of Simplified DMFT Indices in Epidemiological Surveys of Dental Caries. Revista de Saude Publica, 39, 285-292. https://doi.org/10.1590/S0034-89102005000200021 